\title{
Histopathological distribution of thyroid cancers: A retrospective analysis of 570 patients
}

Ozlem Karaca Ocak ${ }^{1}, \quad$ Hasan Ergenc ${ }^{2}$, Zeynep Ergenc $^{2}, \quad$ Feyzi Gokosmanoglu ${ }^{3}$,

${ }^{1}$ Department of General Surgeon, Medicana International Samsun Hospital, Samsun, Turkey

${ }^{2}$ Department of Internal Medicine, Ayancik Government Hospital, Sinop, Turkey

${ }^{3}$ Department of Endocrinology and Metabolic Diseases, Biruni University Faculty of Medicine, Istanbul, Turkey

\section{A BSTRACT}

Aim: Thyroid cancers are the most commonly encountered endocrine system malignancies. The incidence continues to rise worldwide. Our aim in this study is to investigate the frequency and histopathological subtypes of thyroid cancer in our clinic.

Methods: The present study was conducted with 3614 patients who were followed up in our endocrinology and general surgery clinic and operated with the diagnosis of multinodular and/or nodular goiter between 2015 and 2021. The histopathological types and information of patients diagnosed with thyroid cancer were obtained retrospectively from the pathology reports. Among the patients included in the study, a total of 570 people who were reported to have thyroid cancer due to histopathology were included in the study.

Results: The data of a total of 3614 biopsy reports were examined for the study. Among these patients, 570 (421 females, 149 males) were operated and whose pathology reports were accessed were included in the study. The mean age of the patients was $49.12 \pm 10.4$ years. As a result of the operations, malign postoperative tissue histopathology was $98.9 \%(n=564)$, and uncertain malignancy potential was reported to be $1.0 \%(n=6)$. In our study, the histopathological distribution of thyroid cancers was as follows; thyroid papillary cancer 89.4\% $(n=510)$, follicular cancer $7.3 \%(n=42)$, medullary cancer $2.1 \%(n=12)$, and malignancy potential uncertain $1.0 \%(\mathrm{n}=6)$.

Conclusion: The results of our study suggest that thyroid cancers are more common in women in our country, in parallel with the similar rates reported in the literature, with the increase worldwide.

Key words: Thyroid neoplasms, carcinoma, pathology, histopathological distribution, regional differences.

Dr. Ozlem Karaca Ocak

Department of General Surgeon, Medicana International Samsun Hospital, Samsun, Turkey

E-mail: karacaocakozlem@gmail.com

Received: 2021-05-18/Revisions: 2021-07-30

Accepted: 2021-08-07 / Published online: 2021-10-01

\section{Introduction}

Thyroid Cancer (TC) incidence is increasing rapidly; however, the mortality rate remains stable. There are five main histological types of TC: papillary, follicular, poorly differentiated, anaplastic (the most aggressive form), and medullary thyroid cancer $[1,2]$. The prevalence of $\mathrm{TC}$ is approximately three times more in women than in men, and it is the fifth most common cancer in women [3]. According to the health data of 2015, TCs represent $12.1 \%$ of all cancers in women and $2.7 \%$ of all cancers in men in Turkey [4]. TC is the most common endocrine malignancy, constituting $2.9 \%$ of all new cancer cases in the USA. These cancers have an excellent prognosis with a 5-year survival rate of $98.3 \%$. Differentiated thyroid cancers originate from follicular epithelial cells and account for more than $90 \%$ of all the thyroid malignancies $[5,6]$. 
The prevalence of $\mathrm{TC}$ is high in areas where nodular goiter is endemic. In this respect, it is important that Turkey is an endemic goiter region. TCs are 3-4 times more common in women than in men [7]. The purpose of the present study was to investigate the prevalence of TCs and histopathological cancer types in our clinic.

\section{Materials and methods}

A total of 3614 patients who were followed up in our Endocrinology and General Surgery Clinic diagnosed with multinodular and/or nodular goiter between 2015 and 2021 were selected to include in the present study. Among these patients, 570 people reported TCs in pathology reports and were included in the study. The demographic characteristics, preoperative

Thyroid fine needle biopsy (TFNABx), and postoperative histopathology reports were collected from patient files and electronic records. The Clinical Research Ethics Committee approval of Medicana International Samsun hospital was obtained with the decision at the meeting with the number 7133 - 1 (20.04.2020-08). The study was conducted in line with ethical rules.

Among the patients, those with follicular neoplasia, suspected malignancy, and malignant cytological characteristics were operated on. Some of the patients had benign results in biopsies and were operated on because of aesthetic concerns, compression findings, and other reasons. Among these patients, 570 people reported to have TCs in pathology reports were included in the study.

\section{Statistical analyses}

The Chi-Square was used in the categorical data, and the Non-Paired Students $\boldsymbol{t}$-Test was used to compare the continuous variables. The average number of positive criteria in malignant lesions was compared with the Non-Paired Students $\boldsymbol{t}$-Test. One-Way ANOVA and Multiple $t$-Tests were used for the comparison of TC subtypes. Statistical significance level was taken as $\mathrm{p}<0.05$.

\section{Results}

The data of patients who underwent a total of 3.614 biopsies were analyzed for the study. Among these patients, 570 (421 women, 149 men), who were operated and whose pathology results were available, were included in the study. The mean age of the patients was 49.12 \pm 10.4 . The demographic characteristics of the cases are shown in Table 1.

Table 1. Demographic and hematologic characteristics of the cases.

\begin{tabular}{|l|c|}
\hline Parameters & N \\
\hline Gender, Female/Male & $421 / 149$ \\
\hline Age (years) & $49,12 \pm 10,4$ \\
\hline TSH, mIU/L & $2,13 \pm 1,5$ \\
\hline Anti-TPO, IU/mL & $121,6 \pm 33,9$ \\
\hline Anti-TG, IU/mL & $87,2 \pm 12,5$ \\
\hline
\end{tabular}

Anti-TPO: Anti-thyroid peroxidase antibody, Anti-TG: Anti-thyroglobulin antibody.

Among the 570 patients who were included in the study, the preoperative TFNABx results were benign in $0.1 \%(n=1)$, Follicular, Hurthle cell neoplasia or suspected in $2.8 \%(\mathrm{n}=16)$, suspected malignancy in $46.4 \%(\mathrm{n}=265)$, and malignant in $50.5 \%(\mathrm{n}=288)$ patients (Figure 1A). Postoperative tissue histopathology was reported as malignant in $98.9 \%(n=564)$, and with unclear malignancy potential in $1.0 \%(\mathrm{n}=$ 6) patients. In our study, the histopathological distribution of the thyroid cancer was thyroid papillary cancer in $89.4 \%(n=510)$ (Figure 1B), follicular cancer in $7.3 \%(\mathrm{n}=42)$, and 
medullary cancer in $2.1 \%(\mathrm{n}=12)$ patients (Figure 1C and D). The TFNABx reports of the cases and the histopathological distribution of the thyroid cancer are shown in Table 2.

We found that thyroid cancers were most common in the 41-50 age group. Half of the cancer prevalence was detected in the 31-50 age group. The distribution of cancers according to age is shown in Table 3. We found that the autoimmunity was $24 \%$, and the frequency of goiter was $3.8 \%$ in women with thyroid cancers. The distribution of the prevalence of autoimmunity and goiter in thyroid cancer cases according to gender is shown in Table 4 . We found the frequency of autoimmunity to be $30 \%$ in our study, and the frequency of goiter was $5.9 \%$ in thyroid cancers. The prevalence of autoimmunity, goiter, and histopathological distribution in thyroid cancer is shown in Table 5. We found the multicentricity rate to be $23.2 \%$ in thyroid cancer. In thyroid cancer cases, cancer histology shows the distribution of goiter and autoimmunity. Other pathological characteristics are shown in Table 6.

Table 2. Fine needle biopsy reports and histopathological distribution of thyroid cancers.

\begin{tabular}{|l|c|c|c|c|}
\hline Parameters & Papillary & Follicular & Medullary & $\begin{array}{l}\text { Malignity } \\
\text { potential } \\
\text { unknown }\end{array}$ \\
\hline TIIABx benign, $\mathbf{n = 1}$ & - & $\mathbf{1}$ & - & - \\
\hline $\begin{array}{l}\text { TIIABx follicular, Hurthle cell } \\
\text { neoplasia or suspicion, } \mathbf{n = 1 6}\end{array}$ & $\mathbf{6}$ & $\mathbf{9}$ & - & $\mathbf{1}$ \\
\hline TIIABx malignity suspicious, $\mathbf{n = 2 6 5}$ & $\mathbf{2 3 7}$ & $\mathbf{1 7}$ & $\mathbf{8}$ & $\mathbf{3}$ \\
\hline TIIABx malign, $\mathbf{n = 2 8 8}$ & $\mathbf{2 6 7}$ & $\mathbf{1 5}$ & $\mathbf{4}$ & $\mathbf{2}$ \\
\hline Total (F/M) & $510(382 / 128)$ & $42(31 / 11)$ & $12(7 / 5)$ & $6(4 / 2)$ \\
\hline
\end{tabular}

TC: Thyroid cancer, TIIABx: Thyroid fine-needle aspiration biopsy, F: female, M: male.

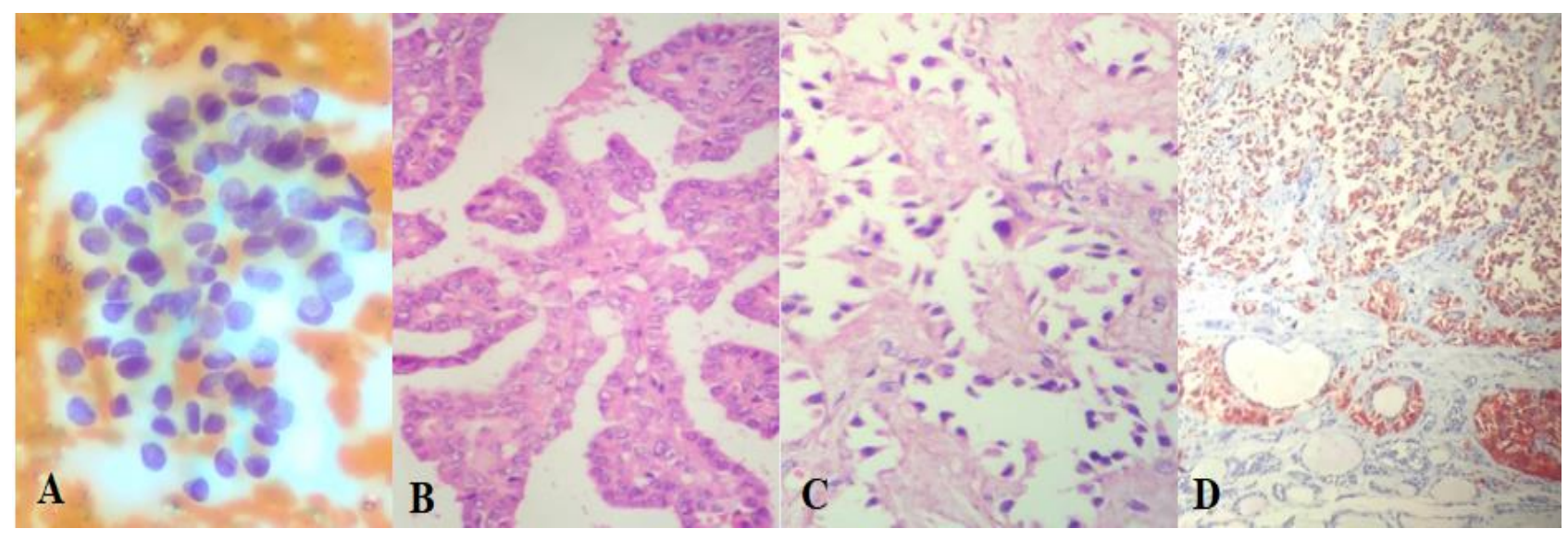

Figure 1. A) Fine needle aspiration biopsy, malignant (consistent with papillary carcinoma). B) Tissue histopathology; papillary carcinoma. C) Tissue histopathology; follicular carcinoma. D) Immunohistochemically examination, chromogranin A (+); medullary carcinoma. 
Table 3. Distribution of thyroid cancers according to the age range.

\begin{tabular}{|c|c|c|c|c|c|}
\hline \multirow[b]{2}{*}{ Histological types } & \multicolumn{5}{|c|}{ Age $(\mathrm{N} / \%)$} \\
\hline & $18-30$ & $31-40$ & $41-50$ & $51-60$ & $61-75$ \\
\hline Follicular carcinoma & $6(1.0)$ & $11(1.9)$ & $16(2.6)$ & $7(1.2)$ & $2(0.3)$ \\
\hline Papillary carcinoma & $52(9.1)$ & 85 (14.9) & $210(36.8)$ & $113(19.8)$ & $50(8.7)$ \\
\hline Medullary carcinoma & - & $2(0.3)$ & $3(0.5)$ & $5(0.8)$ & $2(0.3)$ \\
\hline $\begin{array}{l}\text { Malignity potential } \\
\text { obvious thyroid } \\
\text { carcinoma }\end{array}$ & $1(0.1)$ & $1(0.1)$ & $2(0.3)$ & $2(0.3)$ & - \\
\hline
\end{tabular}

Table 4. Distribution of autoimmunity and goiter according to gender in thyroid cancer cases.

\begin{tabular}{|l|c|c|c|}
\hline Histological types & Male & Female & $\begin{array}{c}\text { Ratio } \\
\text { (Female: } \\
\text { Male) }\end{array}$ \\
\hline Autoimmune & 34 & 137 & $4,02: 1$ \\
\hline Goiter & 12 & 22 & $1,8: 1$ \\
\hline Thyroid carcinomas & 146 & 424 & $2,9: 1$ \\
\hline
\end{tabular}

Table 5: Distribution and frequency of autoimmunity in goiter and histopathologic thyroid cancers.

\begin{tabular}{|l|c|}
\hline Histological types & $\begin{array}{c}\text { Frequency } \\
\text { (N/\%) }\end{array}$ \\
\hline Autoimmune & \\
Hashimoto thyroiditis & $84(14.7)$ \\
Lymphocytic thyroiditis & $56(9.2)$ \\
Graves' diseases & $31(5.4)$ \\
\hline Goiter & $8(1.4)$ \\
Simple colloid goiter & $26(4.5)$ \\
Multinodular goiter & $42(7.3)$ \\
\hline Neoplastic, malignant & $510(89.4)$ \\
Follicular carcinoma & $12(2.1)$ \\
Papillary carcinoma & $6(1.0)$ \\
Medullary carcinoma & \\
Malignity potential obvious & 775 \\
\hline thyroid carcinoma & \\
\hline Total &
\end{tabular}

Table 6. Pathologic features of the patients with thyroid carcinoma.

\begin{tabular}{|l|c|}
\hline Pathologic features & Frequency (\%) \\
\hline Multicentricity & 23.2 \\
\hline Tumor capsule invasion & 5.6 \\
\hline Lymphatic invasion & 6.7 \\
\hline Vascular invasion & 6.4 \\
\hline Extrathyroidal invasion & 3.8 \\
\hline
\end{tabular}

\section{Discussion}

Thyroid cancers make up the most common malignancy in the endocrine system and account for $3.4 \%$ of all cancers diagnosed annually on a global scale [8]. It has been detected in recent years that the increasing incidence of thyroid cancer and over-diagnosis has begun to slow down [9]. The rapid increase in TC incidence was parallel to the detected thyroid nodules, the more common use of thyroid ultrasonography, and the increase in the incidence of biopsy [10].

Thyroid carcinomas were most frequently detected in the 41-50 age group in our study. We found the prevalence of autoimmunity as $30 \%$, and the frequency of goiter was $5.9 \%$ in thyroid cancer cases. The prevalence of autoimmunity in women was $24 \%$, and that of goiter was $3.8 \%$, consistent with the literature data. We also found the multicentricity rate as $23.2 \%$ in thyroid carcinomas. These findings are in line with the current literature findings. Papillary thyroid carcinoma is the most common histological type, which accounts for approximately $85-95 \%$ of thyroid malignant neoplasms. The 10-year survival rate is over $90 \%$ in these cancers. These tumors generally have silent biological behavior [11,12]. In previous studies, papillary carcinoma was more common in women at a rate of $76.40 \%$ and $23.59 \%$ in men [13]. In the present study, papillary carcinoma subtype was the most common histologic type at $89.4 \%$ (510/570). 
We showed in this study that it is more common in women at a rate of $74.9 \%$ (382/510). The rate of papillary carcinoma was $37.5 \%(6 / 16)$ in cases with TFNABx follicular, Hürthle cell neoplasia or suspected malignancies, $89.4 \%$ (237/265) in patients with suspected malignancies, and 92.7\% (267/288) in those with malignancies.

Follicular carcinoma represents approximately $5-10 \%$ of thyroid malignancies and can be detected at much higher rates, such as $25-40 \%$ in areas with intense iodine deficiency $[14,15]$. Follicular carcinoma is a more aggressive type of thyroid cancer with an increasing prevalence. Unlike papillary thyroid cancer, which spreads over lymphatics, follicular thyroid cancer is more aggressive because it can metastasize through vascular invasion [16]. In our study, we detected that the Follicular Carcinoma Subtype was at a rate of $8.2 \%(42 / 570)$. We showed that it is more prevalent in women at a rate of $73.8 \%$ (31/42). The rate of follicular carcinoma was $56.2 \%(9 / 16)$ in cases with TFNABx follicular carcinoma, Hürthle cell neoplasia, or suspected $6.4 \%(17 / 265)$ in patients with suspected malignancies, and 5.2\% (15/288) in those with malignancies.

Medullary thyroid carcinoma is a rare type of tumor that originates from thyroid $\mathrm{C}$ cells and constitutes $2-4 \%$ of all malignant thyroid tumors. Medullary carcinoma may occur sporadically or be inherited as a part of MEN Type 2 syndrome [17,18]. In our study, the medullary carcinoma subtype was found to be $2.1 \%(12 / 570)$. It was also shown that it is more prevalent in women with a rate of $58.3 \%(7 / 12)$. We found that the rate of medullary carcinoma was $3.0 \%(8 / 265)$ in those with suspected malignancies and $1.3 \%(4 / 288)$ in those with malignancies. In previous studies, the "welldifferentiated tumor with uncertain malignant potential" term is used for lesions with follicular patterns of the thyroid, which cannot be diagnosed easily as benign or malignant because of the lack of suspicious nuclear changes and capsular or vascular invasion. The basic reason behind this recommendation is that, clinically, such lesions behave benignly with an excellent prognosis [19]. In our study, it was found that the uncertain malignancy potential was $1.0 \%(n=6)$.

This study had several limitations. It was designed retrospectively and must be supported with prospective studies. Also, the anamnesis of the patients and other comorbid diseases could not be evaluated in detail because the study was conducted retrospectively.

As a result, TC covers a wide range of diseases that have varying prognoses. Many patients with this disease have excellent overall survival rates. It is increasing in our country at similar rates in accordance with the literature parallel to the worldwide increase. It was shown in the present study that it is detected more frequently in women with a similar histopathological distribution.

Funding: The author(s) received no financial support for the research, authorship, and/or publication of this article.

Conflict of Interest: The authors declare that they have no conflict of interest.

\section{Ethical statement:}

The study was approved by Local Clinical Research Ethics Committee (Date and Decision Number: 20.04.2020-7133), and written informed consent was obtained from each subject.

\section{Open Access Statement}

This is an open access journal which means that all content is freely available without charge to the user or his/her institution under the terms of the Creative Commons Attribution NonCommercial License 
(http://creativecommons.org/licenses/bync/4.0). Users are allowed to read, download, copy, distribute, print, search, or link to the full texts of the articles, without asking prior permission from the publisher or the author.

Copyright (c) 2021: Author (s).

\section{References}

[1]Roman BR, Morris LG, Davies L. The thyroid cancer epidemic, 2017 perspective. Curr Opin Endocrinol Diabetes Obes. 2017;24(5):332-36.

[2]Chmielik E, Rusinek D, OczkoWojciechowska M, et al. Heterogeneity of Thyroid Cancer. Pathobiology. 2018;85(12):117-29.

[3]Salamanca-Fernández E, RodriguezBarranco M, Chang-Chan YL, et al. Thyroid Cancer Epidemiology in South Spain: a population-based time trend study. Endocrine. 2018; 62(2): 423-31.

[4]Sağlık İstatistikleri Yıllığı 2017, T.C. Sağlık Bakanlığı, https://sbsgm.saglik.gov.tr/TR,50773/saglik istatistikleri-yilligi-2017-

yayinlanmistir.html (ET: 18.03.2019).

[5]SEER Cancer Stat Facts. Thyroid cancer. Bethesda, MD: National Cancer Institute, https://seer.cancer.gov/statfacts/ht ml/thyro.html (accessed 9 October 2020).

[6]Xing M, Haugen BR, Schlumberger M. Progress in molecular-based management of differentiated thyroid cancer. Lancet. 2013;23:381(9871):1058-69.

[7]Şahin N, Üçer Ö. Malatya'da yapılan tiroidektomilerde tiroid kanseri sıklığı. Dicle Med J. 2013; 40 (4): 570-73.

[8]National Cancer Institute: Surveillance, Epidemiology, and End Results Program. https://seer.cancer.gov/statfacts/html/thyro. html (accessed April 25, 2017).
[9]Shi LL, DeSantis C, Jemal A, et al. Changes in thyroid cancer incidence, post-2009 American Thyroid Association guidelines. Laryngoscope. 2017;127(10):2437-41.

[10]Guth S, Theune U, Aberle J, et al. Bamberger CM. Very high prevalence of thyroid nodules detected by high frequency (13 MHz) ultrasound examination. Eur J Clin Invest. 2009;39(8):699-706.

[11] Rosai J, Albores Saavedra J, Asioli S, et al. WHO classification of tumours of endocrine organs, WHO/IARC classification of tumours (4th), vol 10. International Agent for Research on Cancer. World Health Organization, Lyon: 2017;81-91.

[12]Dedivitis RA, Matos LL, GuimarÃes AV, et al. Neck recurrence in papillary thyroid carcinoma. Rev Col Bras Cir. 2020;47:e20202545.

[13] Ito Y, Fukushima M, Kihara M, et al. Investigation of the prognosis of patients with papillary thyroid carcinoma by tumor size. Endocr J. 2012;59 (6):457-64.

[14]Baloch ZB, LiVolsi VA. Thyroid and Parathyroid. In: Mills SE, Greenson JK, Hornick JL, Longacre TA, Reuter VE, editors. Sternberg's Diagnostic Surgical Pathology. 6th ed. Philadelphia, USA: Wolters Kluwer Health. 2015; 539-97.

[15]Kilfoy BA, Devesa SS, Ward MH, et al. Gender is an age-specific effect modifier for papillary cancers of the thyroid gland. Cancer Epidemiol Biomarkers Prev. 2009;18(4):1092-100.

[16]Zanotti-Fregonara P, Hindié E, Faugeron I, et al. Update on the diagnosis and therapy of distant metastases of differentiated thyroid carcinoma. Minerva Endocrinol. 2008;33(4):313-27.

[17] Ceolin L, Duval MADS, Benini AF, et al. Medullary thyroid carcinoma beyond surgery: advances, challenges, and 
perspectives. Endocr Relat Cancer. 2019;26(9):499-18.

[18] Viola D, Elisei R. Management of Medullary Thyroid Cancer. Endocrinol Metab Clin North Am. 2019;48(1):285-301. [19] Yassin Fel-Z. Diagnostic criteria of well differentiated thyroid tumor of uncertain malignant potential; a histomorphological and immunohistochemical appraisal. J Egypt Natl Canc Inst. 2015;27(2):59-67. 